\title{
Is the Body Composition and FMS Scores Useful for Evaluation of Effort Capacity and Injury Risk In Soldiers?
} \author{
Agnieszka $\mathrm{MS}^{4}$, Krupa Paweł MS ${ }^{5}$, Jerzy Bertrandt $\mathrm{PhD}^{1}$ \\ ${ }^{1}$ Military Institute of Hygiene and Epidemiology, Kozielska 4 Street, 01-163 Warsaw, Poland \\ ${ }^{2}$ Orthopaedic and Rehabilitation Sports Centre "Enel-Sport" Lazienkowska 3 Streets, 00-449 Warsaw, Poland \\ ${ }^{3}$ Faculty of Mechatronics, Warsaw University of Technology, Św. Andrzeja Boboli 8 Street, 02-525 Warsaw, Poland \\ ${ }^{4}$ Centrum Fizjoterapii Fizjofit Sp. z o.o., Szparagowa 19 Street, 44-141 Gliwice, Poland \\ ${ }^{5}$ Medkonsulting Tanita Polska, Jana Ludygi-Laskowskiego 21 Street, 61407 Poznań, Poland
}

Maculewicz Ewelina $\mathrm{PhD}^{1 *}$, Szarska Ewa $\mathrm{PhD}^{1}$, Rzepka Remigiusz $\mathrm{PhD}^{2}$, Lorenz Katarzyna $\mathrm{BSc}^{3}$, Szynkolewska

DOI: $10.36348 /$ jaspe.2020.v03i01.002

| Received: 11.01.2020 | Accepted: 18.01.2020 | Published: 24.01.2020

*Corresponding author: Maculewicz Ewelina PhD

\section{Abstract}

The main goal of military physical training is balancing the need to improve and maintain a high fitness level whilst minimizing injury risk. Injury risk increase is dependent on inter alia movement quality. The study group was composed of 54 soldiers with an average age of 34,7 $\pm 6,33$ who served in the Polish Army Land Forces. The purpose of this study was to determine if body composition data, Functional Movement Screen results as well as fitness test results confirm their practical application for evaluation of physical condition of soldiers and their predisposition to injury. Furthermore, based on gathered data, we attempted to verify if there was a correlation between body composition or Functional Movement Screen scores and physical efficiency. The average distance for the Yo-Yo test was 827,4 m. The average FMS score was 14,6 $\pm 2,24$. The FMS scores ranged from 10 to 19 points. Based on received FMS results, soldiers were divided into 3 groups. Group I (n-17) comprised of soldiers who received less than 14 points on a 21 -point scale. Group II (n-26) comprised of soldiers who received between 14 and 16 points, and group III (n-11) included subjects who scored above 17 points. Based on the obtained results, we conclude that the body composition analyser will be more useful for a quick, initial assessment of exercise capacity than results of the Functional Movement Screen. Examination using the body composition analyser provides data correlating with the exertion capacity of subjects and is less time consuming.

Keywords: Soldiers, body composition, FMS, injury, fitness level.

Copyright @ 2020: This is an open-access article distributed under the terms of the Creative Commons Attribution license which permits unrestricted use, distribution, and reproduction in any medium for non-commercial use (NonCommercial, or CC-BY-NC) provided the original author and source are credited.

\section{INTRODUCTION}

Physical activity with optimal frequency, duration and intensity improves physical performance. The main goal of military physical training is balancing the need to improve and maintain a high fitness level whilst minimizing injury risk [1]. Musculoskeletal injuries are the leading cause of decreased combat readiness among American soldiers. The Secretary of Defence established reduction of medical cases by $50 \%$ within 2 years as a main goal in 2003[2]. The first step of this program was to understand the activities related to injuries and injuries' causes as well as to identify the demographic and physical profile of injured soldiers. The second step was to prepare a military physical training injury prevention program. Effective injury prevention should be conducted with a multidisciplinary approach, addressing many areas of military activities [3].

Based on statistics, musculoskeletal injuries were the leading factor in soldier's absence from the service with recreational sports, physical training and falls their main reasons [4]. Musculoskeletal injuries are serious medical and social problems, generating significant costs related to work absence, treatment and rehabilitation. Injury risk increase is dependent on inter alia movement quality. There are various ways to assess quality of general and specific movement patterns. One of the most popular and utilized tests used to screen movement patterns is the Functional Movement Screen (FMS). The FMS was introduced by Cook in the athletic population more than 10 years ago [5]. It is a screening tool consisting of seven specific tests to assess an individual's overall functional 
movement quality. The following tests are included in the FMS screen:

1. Deep squat

2. Hurdle step

3. Inline lunge

4. Shoulder mobility

5. Active straight leg raise (ASLR)

6. Stability Push up

7. Rotary stability

\section{All tests are evaluated with the following scale}

- 3 - test performed according to established criteria

- 2 - test performed with compensations

- 1 - inability to perform test according to established criteria

- 0 - pain during performing the test or during provocative test (selected tests).

The FMS helps to identify dysfunctional patterns, asymmetries and weak links related to mobility and coordination. The overall score as well as specific tests' scores determine corrective exercise program helping to improve movement quality and decrease injury risk. American Army introduced the FMS successfully; was able to identify main dysfunctions as well as asymmetries and implement adequate corrective programs. Lisman et al. [6] confirmed that low FMS scores significantly increased risk of injury.

Obesity and excessive weight is another risk injury factor among soldiers [7-11]. American Army has implemented the Army Weight Control Program (AWCP) since the 1980, and initially recorded soldiers' body mass index (BMI) but now body fat percentage (fat standard) is considered more important. American Army monitors both indices and verifies against limits for military services. Access to body analyzers enables precise measurement of body tissue proportion.

Polish Army undertook formation of a new service branch i.e. Territorial Defence Forces (hereinafter: TDF) amounting to 50,000 soldiers in the year 2015. Territorial Defence Forces have been recruiting civil volunteers of various age groups, diverse fitness levels and regardless of previous military experience. TDF recruiters faced a challenge related to simple and quick yet accurate evaluation of recruit's physical potential.

The purpose of this study was to determine if body composition data, Functional Movement Screen results as well as fitness test results confirm their practical application for evaluation of physical condition of soldiers and their predisposition to injury. Furthermore, based on gathered data, we attempted to verify if there was a correlation between body composition or Functional Movement Screen scores and physical efficiency.

\section{MATERIALS AND METHODS}

The study group was composed of 54 soldiers, aged $34,7 \pm 6,33$ on average, who served in the Polish Army Land Forces. All subjects were examined with the Tanita MC $980^{\mathrm{TM}}$ body analyzer and performed the FMS $^{\mathrm{TM}}$ test, followed by the Yo-Yo intermittent, progressive running test. The research was approved by the bioethics commission.

The TANITA MC $980^{\mathrm{TM}}$ body analyzer allows analysing entire body or parts of it. The following body data can be collected: body mass, BMI, body fat percentage, visceral fat rating and water content. For body parts analysis the following data can be acquired: segmental muscle mass, estimation of muscle mass in extremities and muscle mass index.

The FMS (Functional Movement Screen) is used for evaluation of quality of movement patterns. It consists of 7 tests which allow estimating coordination, mobility and stability. The FMS is performed without a warm-up, in a sportswear (shorts) and wearing flat-sole shoes [12]. The total score for screen consisted of the sum of 7 tests; in case of evaluation of asymmetrical tests (where each side is evaluated separately), the lower score was transferred to the total sum.

For evaluation of fitness level, a progressive running-based intermittent test (Yo-Yo Level 1) was carried out. The test is performed by running at an increased pace for a distance of 20 meters. The subject starts from the starting line and must reach the mid line before a beep signal and return to the start line. Subsequent to every 40 meters run (i.e. with one change of direction) the subject rests for 8 seconds. The time allowed for the run is progressively reduced over the next stages. The test ends when the subject is no longer able to keep the pace or quits.

All participants signed a written consent for participation in this study. We collected additional information regarding health and physical condition of all subjects.

\section{STATISTICAL ANALYSIS}

We carried out all statistical calculations using Statistica 6.0 for Windows. Results are presented as means $\square \square$ standard deviations ( \pm SD). We compared the differences between the mean values of tested parameters in groups using the Mann-Whitney U test. We investigated the correlations between parameters using the Spearman's rank correlation; $\mathrm{p} \leq 0,05$ was considered significant.

\section{RESULTS AND DISCUSSION}

Table 1 presents an average data of selected anthropometric data of subjects. 
Table-1: Anthropometric data for the study group ( \pm SD)

\begin{tabular}{|c|c|c|c|c|c|c|c|c|c|}
\hline Age & $\begin{array}{c}\text { Height } \\
\mathbf{~ c m}\end{array}$ & $\begin{array}{c}\text { Weight } \\
\mathbf{~ k g}\end{array}$ & $\begin{array}{c}\text { BMI } \\
\mathbf{k g} / \mathbf{m}^{2}\end{array}$ & $\begin{array}{c}\text { Visceral fat } \\
\text { rating }\end{array}$ & $\begin{array}{c}\text { Body fat } \\
\mathbf{\%}\end{array}$ & $\begin{array}{c}\text { Water } \\
\mathbf{\%}\end{array}$ & $\begin{array}{c}\text { Muscle mass } \\
\mathbf{\%}\end{array}$ & Yo-Yo distance m & FMS score \\
\hline 34,7 & 178,3 & 81,5 & 25,7 & 6,4 & 19,7 & 57,3 & 76,3 & 827,4 & 14,6 \\
$\pm 6,33$ & $\pm 5,98$ & $\pm 11,41$ & $\pm 3,38$ & $\pm 3,17$ & $\pm 5,44$ & $\pm 4,39$ & $\pm 5,11$ & \pm 449 & $\pm 2,24$ \\
\hline
\end{tabular}

FMS - Functional Movement Screen

BMI - Body Mass Index

Yo-Yo test - intermittent progressive running test

The average distance for the Yo-Yo test was $827,4 \mathrm{~m}$ and was characterized by high SD values. Results ranged from 280 to 2460 meters. The average FMS score was $14,6 \pm 2,24$. The FMS scores ranged from 10 to 19 points. Based on received FMS results, soldiers were divided into 3 groups. Group I (n-17) comprised of soldiers who received less than 14 points on a 21-point scale. Group II (n-26) comprised of soldiers who received between 14 and 16 points, and group III (n-11) included subjects who scored above 17 points.

Over $30 \%$ of the examined soldiers were characterized by low efficiency and unsatisfactory fitness of the movement apparatus (group I). Almost half of the subjects $(48.1 \%)$ were qualified to the group
II. Only $20 \%$ of soldiers (group III) revealed good efficiency and their movement apparatus shown only minor irregularities.

Statistical analysis shown significant differences in FMS scores amongst these 3 groups. The average age of groups I and III was significantly different and subjects in latter group were the youngest. Furthermore, group III subjects obtained the best results not only in the FMS test but in the Yo-Yo test as well. The distance covered by group III was significantly longer as compared to remaining groups. As far as body composition is concerned we identified a statistical difference between groups I and III in regard to the average visceral fat ratio and water content (Table 2).

Tab-2: Average anthropometric data for selected 3 FMS groups ( \pm SD)

\begin{tabular}{|c|c|c|c|c|c|c|c|c|c|}
\hline $\begin{array}{c}\text { Points } \\
\text { FMS }\end{array}$ & $\begin{array}{c}\text { Age } \\
\text { years }\end{array}$ & $\begin{array}{c}\text { Height } \\
\mathbf{c m}\end{array}$ & $\begin{array}{c}\text { Weight } \\
\mathbf{k g}\end{array}$ & $\begin{array}{c}\text { BMI } \\
\mathbf{k g} / \mathbf{m}^{\mathbf{2}}\end{array}$ & $\begin{array}{c}\text { Visceral } \\
\text { fat } \\
\text { rating }\end{array}$ & $\begin{array}{c}\text { Body fat } \\
\text { \% }\end{array}$ & $\begin{array}{c}\text { Water } \\
\text { content } \\
\text { \% }\end{array}$ & $\begin{array}{c}\text { Muscle } \\
\text { mass } \\
\text { \% }\end{array}$ & $\begin{array}{c}\text { Distance } \\
\mathbf{m}\end{array}$ \\
\hline $\mathbf{1 2}^{\mathrm{A}^{*}}$ & $36,3^{\mathrm{A}}$ & 178,2 & 82,9 & 26,1 & $7,4^{\mathrm{a}}$ & 21,1 & $56,1^{\mathrm{a}}$ & 75 & $684,7^{\mathrm{A}}$ \\
$\mathbf{\pm 1 , 0 6}^{\mathbf{0}}$ & $\pm 5,59$ & $\pm 7,01$ & $\pm 15,85$ & $\pm 4,66$ & $\pm 3,36$ & $\pm 5,71$ & $\pm 4,16$ & $\pm 5,57$ & $\pm 250,2$ \\
\hline $\mathbf{1 5}^{\mathrm{B} *}$ & 35,2 & 178,9 & 81,5 & 25,5 & 6,4 & 19,8 & 57 & 76,2 & $775,4^{\mathrm{AB}}$ \\
$\mathbf{\pm 0 , 8}^{\mathbf{0}, 8}$ & $\pm 7,17$ & $\pm 5,61$ & $\pm 9,27$ & $\pm 3,01$ & $\pm 3,37$ & $\pm 5,72$ & $\pm 4,68$ & $\pm 5,33$ & $\pm 433,1$ \\
\hline $\mathbf{1 7 , 7}$ & $31^{\mathrm{C}}$ & 176,9 & 79,3 & 25,3 & $4,8^{\mathrm{c}}$ & 17,2 & $59,9^{\mathrm{c}}$ & 78,6 & $1170,9^{\mathrm{C}}$ \\
$\mathbf{\pm 0 , 7 9}$ & $\pm 3,71$ & $\pm 5,38$ & $\pm 8,05$ & $\pm 1,58$ & $\pm 1,47$ & $\pm 3,14$ & $\pm 3,04$ & $\pm 2,99$ & $\pm 572,9$ \\
\hline
\end{tabular}

Significant differences among mean values are marked with different letters $a, b, c \mathrm{p} \leq 0,05 ; \mathrm{A}, \mathrm{B}, \mathrm{C} p \leq 0,01 ; A^{*} B^{*} C^{*}$ $p \leq 0,001$

FMS - Functional Movement Screen BMI - Body Mass Index

Subsequently, we correlated body composition, the FMS score and distance covered during the Yo-Yo test to determine subject's fitness level. We observed a higher number of correlations related to a distance covered than to FMS score values. We identified the highest correlation coefficients for water content, muscle mass and body fat (Table 3 ).

Table-3: Correlation values among body composition, FMS points and the Yo-Yo distance

\begin{tabular}{|l|c|c|}
\hline & Distance & Points \\
\hline Age & $-0,069362$ & $-0,211167$ \\
\hline BMI & $\mathbf{- 0 , 3 3 9 7 2 2}$ & 0,011075 \\
\hline Visceral fat rating & $\mathbf{- 0 , 3 9 1 4 5 5}$ & 0,257845 \\
\hline Body fat \% & $\mathbf{- 0 , 4 7 3 7 9 6}$ & $-0,226949$ \\
\hline Water \% & $\mathbf{0 , 4 8 2 9 0 9}$ & $\mathbf{0 , 2 7 1 2 4 8}$ \\
\hline Muscle mass \% & $\mathbf{0 , 4 7 3 9 2 0}$ & 0,225665 \\
\hline FMS score & $\mathbf{0 , 3 6 9 6 1 6}$ & 1,000000 \\
\hline Yo-Yo test distance & 1,000000 & $\mathbf{0 , 3 6 9 6 1 6}$ \\
\hline
\end{tabular}

Significance of correlation coefficient is marked by bold font

FMS - Functional Movement Screen

BMI - Body Mass Index

YO-YO test - intermittent, progressive running test 
The analysis of correlation coefficients indicates that points from the FMS test are correlated with the distance and water content only. However, the length of the distance is negatively correlated with the BMI, fat percentage and visceral fat content, and positively correlated with muscle mass, water content and FMS points.

One of the parameters analysed during the segmental body mass analysis was lower limbs' muscle mass distribution. We considered the difference between limbs exceeding 500 grams an asymmetry, which is acknowledged as one of the risk factors of injuries. Obesity is another parameter that is injuries' risk factor. The body composition analyzer automatically calculates the BMI value for all subjects. BMI exceeds 30 indicates obesity. We analyzed the percentage share of obese subjects as well as those with a substantial asymmetry by aforementioned groups in order to assess the potential risk of injury among the examined soldiers.

Subjects from group I were characterized by the lowest limb asymmetry and group III was characterised with the highest limb asymmetry. We noticed that overweight subjects (BMI above 30) made $18,8 \%$ of group I and were not present in group III.

The relationship between the distance covered in the Yo-Yo test and occurrence of overweight and obesity drew our attention. We observed the highest percentage of obese people in the group of subjects who achieved the lowest result in the running test and simultaneously we also noted least asymmetries. In the best performing group (III) there were no obese people but we observed the highest percentage of asymmetry.

This study is an initial step for a complex evaluation of Polish Army soldiers with the use of a body composition, fitness test and the FMS.

The American Army study group analyzed the most important risk factors of soldiers' absence from the service. It concluded that the factors influencing risk of injury are as following: high running mileage, low aerobic fitness and endurance, injury, obesity or excessive weight, poor movement quality and pain [13]. The working group [1] found that prevention strategy and optimizing the physical training routine could reduce injuries among soldiers.

Assessment of the FMS movement patterns is one of the new and quick movement quality verification methods. The FMS tests were used in the Polish Army for the first time in 2015[14]. The large range of soldiers' movement patterns point evaluation indicated various deviations. Moreover, analysis of various units of the Polish Armed Forces showed movement pattern quality differences between service branches as well as functions. The introduction of the FMS test as a standard evaluation procedure can be an important step in implementation of a systematic injury risk assessment in the Polish Army.

Excessive weight and obesity are present globally and are one of the most dangerous symptoms observed worldwide $[15,16,11]$.

The National Health Program currently in force in Poland is largely devoted to the fight against overweight and obesity as the main factors generating civilization-related diseases.

Obesity problems in the Polish army are often discussed during conferences and seminars, but there is a lack of specific actions taken to overcome this problem. The United States Army has established a special group called the Army Weight Control Program (AWCP) which main task is to identify risk factors and introduce programs to reduce the number of overweight soldiers.

Review of the literature by Friedl [8] points out that body composition plays an important role in a soldier's readiness status for deployment, regardless of army service. Body composition standards can differ for certain services but optimal values are established and these influence soldier's injuries statistics.

Body composition standards established in the US army are age based and defined in BMI and body fat \% levels [8]. Polish soldier's average results do not exceed the US Army standards in general and are particularly outstanding for soldiers in the age of 30 . The examined Polish soldiers are obliged to participate in morning training sessions. It appears that systematic daily physical activity has had a beneficial effect on the subjects' results.

This effect can be seen when comparing the results of subjects participating in this study with soldiers deployed for mission to Afghanistan, from which up to $68,4 \%$, aged up to 30 , had BMI above 26 points (Table 1)[10].

This positive assessment of the soldiers examined in this work does not change the fact that for $18.8 \%$ of subjects in the low-efficiency group, the BMI value exceeded 30 (Table 4). 
Table-4: Distribution of asymmetry and overweight in examined groups

\begin{tabular}{|c|c|c|}
\hline $\begin{array}{c}\text { Yo-Yo test distance } \\
\mathbf{m}\end{array}$ & $\begin{array}{c}\text { Asymmetry } \\
\mathbf{\%}\end{array}$ & $\begin{array}{c}\text { Overweight } \\
\mathbf{\%}\end{array}$ \\
\hline $\begin{array}{c}\mathbf{6 8 4 , 7} \pm 250,2 \\
\mathrm{n}-17\end{array}$ & 12,5 & 18,8 \\
\hline $\begin{array}{c}\mathbf{7 7 5 , 4} \pm 433,1 \\
\mathrm{n}-26\end{array}$ & 21,4 & 10,7 \\
\hline $\begin{array}{c}\mathbf{1 1 7 0 , 9} \pm 572,9 \\
\mathrm{n}-11\end{array}$ & 30 & 0 \\
\hline \multicolumn{2}{|c|}{ Yo - Yo test - intermittent, progressive running test }
\end{tabular}

Muscle mass composition and symmetry between limbs is a novel way to observe balance and functional symmetry with the use of body composition analysis. Lower limbs muscle mass asymmetry exceeding 100-200g was correlated with the FMS score. Long-lasting asymmetry is considered a significant factor relating to increased risk of injury.

Summing up obtained results, we can conclude that the body composition analyzer will be more useful for a quick initial assessment of exercise capacity than results of the Functional Movement Screen. Examination using the body composition analyzer does not only provide data correlating with the exertion capacity of subjects but is also less time consuming. The data from the body composition analyzer can also be helpful in assessing the movement apparatus and in indicating predisposition to an injury due to a clear asymmetry.

\section{CONCLUSIONS}

Summing up based on current study results and bibliography:

- Body composition and FMS results can be helpful in evaluating soldiers' physical condition,

- Body fat and water content can be predictive values for a soldiers' fitness level,

- A systematic physical fitness program can be effective for a weight management of soldiers and deployment readiness,

- There is a need for implementation of effective evaluation and physical training programs to optimize soldiers' physical condition.

\section{REFERENCES}

1. Knapik, J.J., Rieger, W., Palkoska, F., Van Camp, S., \& Darakjy, S. (2009). United States Army physical readiness training: Rationale and evaluation of the physical training doctrine. J Strength Cond Res; 23,4:1353-1362

2. Copley, G.B., Burnham, B.R., Shim, M.J., \& Kemp, P.A. (2010). Using safety data to describe common injury-producing events examples from the U.S. Army. Air Force. Am J Prev Med; 38 (1S):117-125.

3. Bullock, S.H., Jones, B.H., Gilchrist, J., \& Marshall, S.W. (2010). Prevention of physical training-related injuries. Recommendations for the military and other active populations based on expedited systematic reviews. A J Prev Med; 38;S156-S181

4. Ruscio, B.A., Jones, B.H., Bullock, S.H. (2010). A process to identify military injury prevention priorities based on injury type and limited duty days. Am J Prev Med; 38;S19-S33

5. Cook, G., Burton, L., \& Hoogenboom, B. (2006). Pre-participation screening: The use of fundamental movements as an assessment of function-part 1. N Am J Sports Phys Ther; 1;62-72

6. Lisman, P., O’Connor, F.G., Duester, P.A., \& Knapik, J.J. (2013). Functional Movement Screen and aerobic fitness predict injuries in military training. Med Sci Sports Exerc; 45,4:636-643

7. Friedl, K.E., \& Leu, J.R. (2002). Body fat standards and individual physical readiness in a randomized army sample screening weights, methods of fat assessment, and linkage to physical fitness. Mil Med; 167:994-1000

8. Friedl, K. E. (2012). Body composition and military performance-many things to many people. The Journal of Strength \& Conditioning Research, 26, S87-S100.

9. Hruby, A., Bulathsinhala, L., McKinnon, C. J., Hill, O. T., Montain, S. J., Young, A. J., \& Smith, T. J. (2016). BMI and lower extremity injury in US Army soldiers, 2001-2011. American journal of preventive medicine, 50(6), e163-e171.

10. Szarska, E., Frankiewicz-Jóźko, A., \& Faff, J. (2011). Comparison of selected anthropometric and aerobic fitness indices before and after military mission in Afghanistan. A diagnosis of physical fitness in the contemporary army. Ed.: M. Sokołowski, 245-252.

11. Kovesdy, C.P., Furth, S., \& Zoccali, C. (2017). World Kidney Steering Committee. Obesity and kidney disease: Hidden consequences of the epidemic. Physiology International. Published online March 31

12. Cook, G., Burton, L., \& Hoogenboom, B. (2006). Pre-participation screening: The use of fundamental movements as an assessment of function-part 2. N Am J Sports Phys Ther, 1;132139

13. Zambraski EJ, Yancosek KE. Prevention and rehabilitation of musculoskeletal injuries during military operations and training. The Journal of Strength \& Conditioning Research. 2012 Jul 1;26:S101-6. 
14. Szarska, E., Maculewicz, E., Rzepka, R., \& Szynkolewska, A. (2017). FMS (Functional Movement Screen) test for evaluation of fundamental movement patterns of soldiers from various branches of Polish Armed Forces: a pilot study. Lekarz Wojskowy; 95: 59-63

15. Allender, S., \& Rayner, M. (2007). The burden of overweight and obesity-related ill health in the UKK. Obes. Rev, 8(5):467-473
16. Biela U, Pająk A, Kaczmarczyk-Chałas K, Głuszek J, Tendera M, Wawrzyńska M, Kurjata P, Wyrzykowski B. Częstość występowania nadwagi i otyłości u kobiet i mężczyzn w wielu 20-74 lat. Wyniki programu WOBASZ. Kardiologia Polska (Polish Heart Journal). 2005;63(IV). 